\title{
FAIRBANKS SYSTEM OF INSTRUCTION AT FAIRBANKS COUNTRY DAY
}

\author{
C. J. Conard \\ Fairbanks Country Day
}

\begin{abstract}
The Fairbanks Country Day program is a K-12 private school designed to use a Personalized System of Instruction (PSI) along with computer technology for delivery of basic academic curriculum. In PSI students study individually prescribed lessons using textbooks and supplementary materials, computer-generated exercises and mastery tests. They interact with their teachers primarily on a conference basis, receiving feedback and encouragement and additional instruction as needed. Whole group lectures are presented as a supplement to individualized instruction. Students, teachers, and parents receive daily data on student progress, and, if needed, students are provided with extra incentives and instruction to maintain progress congruent with their skill levels and expected level of performance. Teaching is adjusted as needed based on student performance. In the 1995 and 1996 evaluations, SAT scores for the total battery (reading, math, language, spelling) were from I to 4 years above grade level.
\end{abstract}

\section{Background}

Fairbanks Country Day is a private pre kindergarten through 12th grade school located in San Diego county. It has been in operation since 1986. The programs and procedures used in the school are all performance-driven, that is, the instruction students receive and the rate at which it is provided is determined by an ongoing evaluation of their performance on prescribed learning tasks.

Much of the curriculum is based on the Personalized System of Instruction (PSI) model (Keller, 1968; Keller \& Sherman, 1974). In PSI, students are given independent assignments based on specific objectives. Assignments may be done in any number of ways: in texts, through library or lab research, working individually or in small groups, or in other ways. Each assignment has mastery criteria. When a student completes an assignment, often called a "unit," the student takes a mastery test to assess if the objectives of the unit have been met. If so, the student is given the next assignment; if not, additional work is prescribed. Students progress at individual rates.

Teachers are the managers of learning, rather than lecturers, although on occasion teachers may present material, especially for discussion or enrichment. For

\section{AUTHOR'S NOTE:}

For further information, please address correspondence to: C. J. Conard, Assistant Director, Fairbanks Country Day, P.O. Box 8387, Rancho Santa Fe, Ca 92067, Tel: (619) 756-0500, Email: cconard@fairbanks.org 


\section{CONARD}

reviews of PSI and its efficacy, see Sherman and Ruskin (1978) and Sherman, Ruskin and Semb (1982).

\section{Program Description}

The first curriculum area completely converted to the PSI model was math. As the most extensive de.velopment has been done in this area, it will be used to illustrate the PSI instructional model. However, mastery criteria have also been determined for spelling and vocabulary beginning in first grade and extending through the upper grades. For courses that have a spelling or vocabulary component, such as English, Science, or foreign languages, the spelling or vocabulary portion of tests requires re-study to achieve mastery for performances less than $90 \%$ accurate.

The Fairbanks Country Day math program consists of a continuous, integrated curriculum for K-12 in which the objectives were established through a staff analysis of the critical objectives of existing math texts. Students work through the instructional materials at their own rate; however, criteria for a reasonable expected rate of completion and mastery of materials are established for each student to avoid allowing students to fall behind.

Software developed by the school for placing students at an appropriate level of instruction, tracking their performance, and reporting progress is an integral part of PSI as used at Fairbanks Country Day. To place students at the appropriate level of instruction, teachers enter relevant information about them into the computer. Based on this data, the computer prints a placement or assessment form which consists of individual problems (assignments). Generating each problem individually eliminates issues such as cheating or "rote" learning without the development of problem solving skills. If a student passes all items on a form, a new one is printed until a level is reached at which the student lacks skills. A study sheet is then printed out that tells the student which instructional materials must be completed and provides accompanying assignments. Instructional materials include textbooks and supplementary materials. Assignments directly teach skills associated with new objectives, provide practice, develop fluency, and provide additional problems to develop more generalized problem solving.

After students have completed an assignment, the teacher checks each student's work using the answers provided in the software program, which then determines when the student is ready to go to the next assessment and new assignments. While students wait for this feedback, they work on assignments in other subject matters or work ahead in their text preparing for upcoming assignments.

There is a mastery requirement for acquisition of the stated objectives at the completion of each unit. There are also periodic mastery checks. The software computer program requires that all math objectives be worked correctly a minimum of three times (successively, or in a row, that is, three separate but repeated presentations), spread out over the course and mixed in with other objectives. In addition, there is a "fluency" requirement for certain skills that are components of more complex skills (e.g., multiplication tables), which requires each student to 


\section{FAIRBANKS SYSTEM OF INSTRUCTION}

solve a specified number of problems of addition, subtraction, multiplication, and division in a certain amount of time, the time decreasing as students progress.

Each paper (a problem or assignment generated by the computer) contains the student's name, the date and time of the paper, a graphic representation of the ratings of student performance in chapters or units completed, a cumulative graph indicating performance to date and predicted performance through the completion of the course extrapolated from performance to date. In addition, the number of days ahead or behind the student's expected rate of completion, the number of problems still to be solved, and the projected number of classes needed to complete the book are shown.

The use of PSI at Fairbanks Country Day allows teachers to optimize individualized instruction while decreasing the chance the students will "fall through the cracks." Students are given immediate remedial help as they demonstrate a need and are encouraged to progress at their own rate but are not allowed to languish for long periods of time.

People are often taken aback by the absence of traditional teacher lectures as the mainstay of instruction. Teachers do give lectures but they are typically given as enrichment and supplement to the computer-aided instruction lessons. In addition, because they are not tied to a lecture format, and with the assistance of the computer-generated lessons, teachers are freed to provide ongoing individual attention to students on a daily basis.

\section{Evaluation}

Each day, each teacher rates each student in his or her classes. Three classes of ratings are made: one on actual assignment completion and accuracy, one on task behavior, and one on conduct. In each area, students are given ratings between 1 (well below expectations) to 5 (exceeded expectations). In addition, each day actual performance data on assignment completion and correctness is reported. These are all entered into the computer data system. Progress on these measures is plotted on a cumulative graph reviewed every week by an administrator. If additional instruction is needed, students attend an after school study hall for additional tutoring. If it is determined the student is using the class time effectively but is unable to maintain the expected pace, the pace for the student is adjusted and progress continues to be monitored. In other instances, improved progress is a matter of providing adequate contingent incentives such as daily contracts, earned privileges, and parental involvement. Remediation is immediate and based on ongoing criterion-referenced performance assessment. These data are condensed and incorporated with other information and must be reviewed by teachers and administrators once a week. Parents are also provided these data in the form of weekly reports.

In addition to the daily performance-based evaluations, every student is tested on the Stanford Achievement Test (SAT) annually. Figure 1 gives the SAT scores for 1994-1995 and Figure 2 gives the data for 1995-1996. 
CONARD

\begin{tabular}{c|cccccc}
\hline Grade & $\begin{array}{c}\text { Number } \\
\text { of } \\
\text { students } \\
\text { in grade }\end{array}$ & $\begin{array}{c}\text { Total } \\
\text { Reading } \\
\text { Scores }\end{array}$ & $\begin{array}{c}\text { Total } \\
\text { Math } \\
\text { Scores }\end{array}$ & Language & Spelling & $\begin{array}{c}\text { Complete } \\
\text { Battery }\end{array}$ \\
\hline 1 & 19 & 3.0 & 2.7 & 2.8 & 3.5 & 2.9 \\
2 & 7 & 5.3 & 4.2 & 5.6 & 4.3 & 4.5 \\
3 & 6 & 7.5 & 7.3 & 6.8 & 10.2 & 7.3 \\
4 & 8 & 704 & 8.3 & 10.0 & 7.1 & 8.3 \\
5 & 19 & 8.0 & 8.9 & 10.6 & 8.5 & 9.0 \\
6 & 17 & 7.9 & 12.5 & 9.5 & 8.8 & 9.5 \\
7 & 8 & phs* & 904 & 7.1 & 8.1 & 8.9 \\
8 & 9 & phs & phs & 9.7 & 8.7 & phs \\
9 & 5 & phs & phs & phs & phs & phs \\
10 & 5 & phs & phs & phs & 11.7 & phs \\
11 & nd & nd & nd & nd & nd & nd \\
\hline \multicolumn{7}{r}{} \\
\hline
\end{tabular}

Figure 1. SATScores 1994-1995

\begin{tabular}{|c|c|c|c|c|c|c|}
\hline Grade & $\begin{array}{c}\text { Number } \\
\text { of } \\
\text { students } \\
\text { in grade }\end{array}$ & $\begin{array}{c}\text { Total } \\
\text { Reading } \\
\text { Scores }\end{array}$ & $\begin{array}{c}\text { Total } \\
\text { Math } \\
\text { Scores }\end{array}$ & Language & Spelling & $\begin{array}{c}\text { Complete } \\
\text { Battery }\end{array}$ \\
\hline 1 & 10 & 3.1 & 2.3 & 2.6 & 3.5 & 2.7 \\
\hline 2 & 21 & 5.1 & 3.5 & 3.7 & 7.0 & 3.6 \\
\hline 3 & 10 & 7.1 & 4.3 & 4.5 & 5.9 & 5.3 \\
\hline 4 & 16 & 8.1 & 8.2 & 8.1 & 10.0 & 804 \\
\hline 5 & 17 & 10.2 & 7.9 & 12.1 & 11.3 & 9.1 \\
\hline 6 & 13 & phs* & 9.7 & 9.1 & 8.8 & 9.6 \\
\hline 7 & 23 & 10.8 & 11.1 & 12.1 & 11.1 & 10.2 \\
\hline 8 & 9 & 11.8 & $1 O A$ & 12.5 & 8.7 & 10.2 \\
\hline 9 & 4 & phs & phs & nd & 9.9 & phs \\
\hline 10 & 4 & 9.8 & phs & nd & 8.1 & 10.6 \\
\hline 11 & 4 & phs & phs & nd & phs & phs \\
\hline
\end{tabular}

Figure 2. SAT Scores 1995-1996 


\section{FAIRBANKS SYSTEM OF INSTRUCTION}

These scores indicate students often place more than two years above grade level on the SAT scores. One exception to this tendency may be seen in the scores of the 10th and 11 th grades. School personnel postulate this may occur because many of the upper-grade students are placed at Fairbanks beginning in the 9th or 10th grades and often come to the school because of a history of academic and behavior management problems. Their lower achievement may be a reflection of this history. On the other hand, over time the trend is that these students seem to catch up. This is an area that needs to be examined more carefully. In the future, the school also hopes to obtain control data to compare its students with other students statewide.

The PSI model was implemented in 1992, starting with the Pre-Algebra and Algebra courses. With each phase of development, additional lower grades were added. As each group of students began participating in the program, improvements in their performance have been observed. In addition, the program helps teachers and administrators to identify student academic problems needing additional instruction or incentives before a pattern of failure has been established. Anecdotal reports from teachers indicate that students have begun to generalize to other subjects many of the self-help strategies taught through PSI used in math instruction.

\section{REFERENCES}

Keller, F. (1968). Goodbye teacher. Journal of Applied Behavior Analysis, 1, 7989. http://dx.doi.org/10.1901/jaba.1968.1-79

Keller, F., \& Sherman, J. G. (1974). The Keller plan handbook: Essays on a personalized system of instruction. Menlo Park, CA: Benjamin.

Sherman, J. G., \& Ruskin, R. S. (1978). The instructional design library. The Personalized System of Instruction, 13, Englewood Cliffs, NJ : Educational Technology Publications.

Sherman, 1. G., Ruskin, R. S., \& Semb, G. B. (1982). The personalized system of instruction: 48 seminal papers. Lawrence, KS: TRI Publications. 